\title{
KOMPETENSI GURU DALAM MENGELOLA PEMBELAJARAN AL- QUR'AN HADIST DI MAS SYEKH AHMAD BASYIR PARSARIRAN BATANG TORU
}

\author{
OLEH \\ HERMAN PELANGI, M.Pd \\ NIDN.0118088503 \\ (Dosen Program Studi Pendidikan Agama Ialam UMTS, Padangsidimpuan)
}

\begin{abstract}
This study discusses the problem of teacher competence in managing learning Al-Qur'an Hadist in MAS Sheikh Ahmad Basyir Parsariran Batang Toru. Researchers chose this title because the researchers saw the weakness of Al-Qur'an Hadist teachers in managing learning. The formulation of this research problem is how the competence of teachers in managing learning Al-Qur'an Hadist in MAS Sheikh Ahmad Basyir Parsariran Batang Toru and what efforts of teachers Al-Qur an Hadist in managing learning in MAS Sheikh Ahmad Basyir Parsariran Batang Toru.

The purpose of this study is to know how the competence of Al-Qur'an Hadist teachers in managing learning in MAS Sheikh Ahmad Basyir Parsariran Batang Toru and To find out what efforts of teachers Al-Qur'an Hadist in managing learning in MAS Sheikh Ahmad Basyir Parsariran Batang Toru . The research method used by using descriptive qualitative method while the techniques and data collection tools used are interviews (interviews) and observation and documentation, while the analysis of data in executed by compiling and mengola data, then describe it systematically.

After collecting the data, processing the data and analyzing the data from the research that has been done, the researchers get the result that the competence of teachers in managing learning Al Qur'an Hadith in MAS Sheikh Ahmad Basyir Parsariran Batang Toru, is in the low category, because it is still less in megadakan pretest, lack of use of learning methods, neglect of learning objectives (TPK), lack of media use, and lack of follow-up learning. Efforts are made in the formation of teacher competence in managing the learning of the Qur'an Hadiśt in MAS Sheikh Ahmad Basyir Parsariran Batang Toru is the background of teacher education by suggesting continuing education to a higher level, attending seminars or training, fostering teacher creativity, following the workshop upgrading. Read the relevant books, and will continue education to a higher level, and hold a dialogue with more experienced people to increase their knowledge.
\end{abstract}




\section{PENDAHULUAN}

\section{Latar Belakang Masalah}

Pendididikan merupakan interaksi antara orang dewasa dengan orang yang belum dapat menunjang perkembangan manusia yang berorientasi pada nilai-nilai dan pelestarian serta perkembangan kebudayaan yang berhubungan dengan usaha pengembangan kehidupan manusia.

Dewasa ini pendidikan berkembang semakin pesat dan semakin kompleks, persoalan pendidikan yang dihadapi bukanlah tantangan yang dibiarkan begitu saja, akan tetapi memerlukan pemikiran yang konstruktif demi tercapainya kualitas tujuan pendidikan yang baik. Persoalan yang dimaksud diantaranya adalah kompetensi mengajar guru karena guru sebagai orang yang berhubungan langsung dengan peserta didik seharusnya mempunyai kompetensi yang baik dalam pelaksanaan proses belajarmengajar.

Dalam rangka meningkatkan mutu pendidikan, guru mempunyai peranan yang sangat penting dalam merealisasikan tujuan pendidikan. Guru adalah ujung tombak kegiatan pengajaran di sekolah yang langsung berhadapan dengan siswa, maka tanpa adanya peranan guru kegiatan belajar-mengajar tidak bisa berjalan dengan baik. Seorang guru seharusnya memiliki kompetensi yang baik. Mengajar bukanlah kegiatan yang mudah melainkan suatu kegiatan dan tugas yang berat, penuh dengan masalah, dan penuh tanggung jawab. Kemampuan dan kecakapan sangat dituntut bagi seorang guru. Karena itu seorang guru harus memiliki kecakapan dan keahlian tentang keguruan. Kemampuan dan kecakapan merupakan modal dasar bagi seorang guru dalam melakukan tugasnya.

Berdasarkan observasi yang dilakukan pada MAS Syekh Ahmad Basyir Parsariran Batang Toru dengan guru Al-Qur'an hadist ketika mengajar, peneliti melihat adanya kelemahan guru Al Qur'an Hadist dalam mengelola pembelajaran. ${ }^{1} \mathrm{Hal}$ ini terlihat ketika guru mengajar, seperti kurangnya guru untuk melibatkan siswa secara aktif dalam proses pembelajaran dan memeberikan kesimpulan sehingga banyak siswa yang pasif tidak bisa menguasai pelajaran, serta lemahnya komepetensi akademik yang dimiliki oleh guru.

Dalam Peraturan Menteri Pendidikan Nasional RI Nomor 16 Tahun 2007 tentang Standar Kompetensi Akademik dan Kompetensi Guru dijelaskan bahwa: Kualifikasi Akademik guru SD/MI, SMP/MTs, dan SMA/MA minimum diploma empat (D-4) atau sarjana (S-1). Dalam Penjamin Mutu Pendidikan Nasional (PMPN) ini juga disebutkan bahwa: Guru harus menguasai empat kompetensi utama, yaitu pedagogis, kepribadian, sosial, dan profesional. Keempat kompetensi ini terintegrasi dalam kinerja guru. ${ }^{2}$

Dari hasil wawancara yang peneliti lakukan dengan guru Al-Qur'an Hadist ternyata guru teresebut di lihat dari kompetensi akademiknya hanya memiliki pendidikan madrasah aliyah. ${ }^{3}$

Maka, mengingat pentingnya peningkatan kompetensi guru, sehingga . Guru diharapkan dapat meningkatkan kemampuan mengajar. Dalam usaha ini banyak cara yang dapat

\footnotetext{
${ }^{1}$ Mawar Siregar/ Guru Al- Qur'an Hadist Observasi tanggal 01 April 2014

${ }^{2}$ Jejen Musfah, Peningkatan Kompetensi Guru (Jakarta: Kencana Prenada Media Group, 2012), hal. 3-4

${ }^{3}$ Mawar Siregar/ Guru Al- Qur'an Hadsit Wawancara hari selasa tanggal 01 April 2014
} 
dilakukan, seperti menggunakan metode mengajar yang bervariasi, memberikan penghargaan kepada siswa yang berprestasi, dan lain-lain.

Berdasarkan uraian yang telah dikemukakan diatas, peneliti sangat tertarik untuk menelaah lebih mendalam kompetensi guru dalam mengelola pembelajaran dalam suatu bentuk penelitian yang berjudul "Kompetensi Guru dalam Mengelola Pembelajaran Al-Qur'an Hadiśt di MAS Syekh Ahmad Basyir Parsariran Batang toru.

\section{TINJAUAN PUSTAKA}

\section{A. Pengertian Kompetensi Guru}

Menurut UU Republik Indonesia (RI) Nomor 14 Tahun 2005 menyatakan bahwa kompetensi adalah seperangkat pengetahuan, keterampilan, dan perilaku yang harus dimiliki, dihayati, dan dikuasai oleh guru atau dosen dalam melaksanakan tugas keprofesionalan. ${ }^{4}$

Dalam Peraturan Menteri Pendidikan Nasional RI Nomor 16 Tahun 2007 tentang Standar Kompetensi Akademik dan Kompetensi Guru dijelaskan bahwa: Kualifikasi Akademik guru SD/MI, SMP/MTs, dan SMA/MA minimum diploma empat (D-4) atau sarjana (S-1). Dalam Penjamin Mutu Pendidik Nasional (PMPN) ini juga disebutkan bahwa: Guru harus menguasai empat kompetensi utama, yaitu pedagogis, kepribadian, sosial, dan profesional. Keempat kompetensi ini terintegrasi dalam kinerja guru. ${ }^{5}$

Kompetensi guru menurut Peraturan Pemerintah (PP) No. 19 Tahun 2005 tentang Standar Nasional Pendidikan, pemerintah telah merumuskan empat jenis kompetensi guru, adalah sebagai berikut: ${ }^{6}$

1. Kompetensi Pedagogik, yaitu merupakan Kemampuan dalam pengelolaan peserta didik yang meliputi; a) pemahaman wawasan atau landasan kependidikan; b) pemahaman terhadap peserta didik; c) pengembangan kurikulum/silabus; d) perancangan pembelajaran; e) pelakanaan pembelajaran yang mendidik dan dialogis; f) evaluasi hasil belajar; dan g) pengembangan peserta didik untuk mengaktualisasikan berbagai potensi yang dimilikya.

2. Kompetensi Kepribadian, yaitu Kemampuan kepribadian yang: a) berakhlak mulia; b) mantap, stabil, dan dewasa; c) arif dan bijaksana; d) menjadi teladan; e) mengavaluasi kinerja sendiri; f) mengembangkan diri; dan g) religius.

3. Kompetensi Sosial merupakan kemampuan pendidik sebagai bagian dari masyarakat untuk: a) berkomunikasi lisan dan tulisan; b) menggunakan teknologi komunikasi dan informasi secara fungsional; c) bergaul secara efektif dengan peserta didik, sesama pendidik, tenaga kependidikan, orangtua/wali peserta didik; dan d) bergaul secara santun dengan masyarakat sekitar.

4. Kompetensi Profesional yaitu kemampuan penguasaan materi pembelajaran secara luas dan mendalam yang meliputi: a) konsep, struktur, dan metode keilmuan/teknologi/seni yang menaungi/koheren dengan materi ajar; b) materi ajar yang ada dalam kurikulum sekolah; c) hubungan konsep antarmata pelajaran terkait; d) penerapan konsep keilmuan dalam kehidupan sehari-hari; dan e) kompetisi secara

\footnotetext{
${ }^{4}$ Undang-Undang Republik Indonesia, Nomor. 14 Tahun 2005, Tentang Guru dan Dosen, Bab I Pasal 1 Ayat 10 (Jakarta: Sinar Grafika, 2006), hal. 3

${ }^{5}$ Jejen Musfah, Peningkatan Kompetensi Guru (Jakarta: Kencana Prenada Media Group, 2012), hal. 3-4

${ }^{6}$ Ibid, hal. 30-54
} 
profesional dalam konteks global dengan tetap melestarikan nilai dan budaya nasional.

\section{B. Macam-macam Kompetensi}

Kompetensi guru merupakan gambaran hakikat kualitatif dari prilaku guru atau tenaga kependidikan yang tampak sangat berarti. ${ }^{7}$ Prilaku disini bukan hanya merujuk pada prilaku nyata, tetapi juga meliputi hal-hal yang tidak tampak.

Kompetensi merupakan kemampuan dan kewenangan guru dalam melaksanakan profesi keguruannya, kompetensi guru dapat dibagi menjadi tiga bidang, yaitu:

a) Kompetensi bidang kognitif

Kompetensi ini adalah kemampuan intelektual seperti penguasaan mata pelajaran, disini meliputi beberapa bagian, yaitu: cara mengajar, belajar dan tingkah laku individu, bimbingan dan penyuluhan dikelas, menilai hasil belajar siswa, kemasyarakatan serta pengetahuan umum lainnya. ${ }^{8}$

b) Kompetensi bidang sikap

Kompetensi ini adalah kesiapan dan kesediaan guru terhadap berbagai hal yang berkenaan dengan tugas dan profesinya. Hal ini meliputi menghargai pekerjaan, mencintai dan memiliki perasaan senang terhadap mata pelajaran yang dibinanya, sikap toleransi terhadap mata pelajaran sesama teman, kemauan yang keras untuk meningkatkan hasil pekerjaannya. ${ }^{9}$

c) Kompetensi prilaku

Kompetensi ini adalah kemampuan guru dalam berbagai keterampilan dari prilaku, hal ini meliputi beberapa hal, yaitu: keterampilan mengajar, membimbing, menilai, menggunakan alat bantu, pengajaran bergaul, berkomunikasi, melaksanakan administarasi kelas, dan lain sebagainya. ${ }^{10}$ Perbedaan antara kompetensi kognitif dengan kompetensi ini adalah aspek teori atau pengetahuannya. Pada kompetensi ini yang ditampilkan adalah prektek dan keterampilan melaksanakannya.

\section{METODOLOGI PENELITIAN}

\section{A. Tempat Penelitian}

Penelitian yang penulis lakukan berlokasi di MAS Syekh Ahmad Basyir Parsariran yang terletak di Jln. Sibolga km.29 Desa Parsariran Kecamatan Batang Toru. dengan luas wilayah \pm 6 hektar yang berbatas dengan:

1. Sebelah Utara berbatas dengan jalan raya

2. Sebelah Selatan sungai parsariran

3. Sebelah Barat berbatas dengan jalan raya

4. Sebelah Timur berbatas dengan jalan

\footnotetext{
${ }^{7}$ Hamzah B. Uno, Op.Cit, hal. 67

${ }^{8}$ Ahmad Sabri, Strategi Belajar-mengajar dan Micro Teaching (Jakarta: Quantum Teaching, 2005), hal. 78

${ }^{9}$ Moh. Uzer Usman, Menjadi Guru Profesional (Bandung: PT Remaja Rosda Karya, 2006), hal. 21.

${ }^{10}$ Ibid., hal. 79
} 


\section{B. Jenis Penelitian}

Penelitian ini dilakukan di MAS Syekh Ahmad Basyir Parsariran Batang Toru, dengan mengunakan metode kualitatif deskriptif. Metode deskriptif adalah suatu metode yang mengambarkan gejala-gejala yang ada saat penelitian ini. Menurut Moh. Nasir, Metode Deskriptif adalah suatu metode dalam meneliti status kelompok manusia, suatu objek, suatu kondisi, suatu sistem, pemikiran ataupun suatu kelas peristiwa pada masa sekarang. ${ }^{11}$

Metode ini ditujukan untuk mendeskripsikan, bagaimana kompetensi guru mata pelajaran Al-Qur'an Hadiśt dalam mengelola pembelajaran di MAS Syekh Ahmad Basyir Parsariran Batang Toru.

Untuk menggali data-data di atas, maka peneliti menggunakan teknik-teknik pengumpulan data seperti yang tersebut di bawah ini:

a. Wawancara

Suatu teknik untuk mendapatkan data dengan mengadakan hubungan langsung bertemu muka dengan seseorang. ${ }^{12}$ Bertujuan untuk memperoleh data penunjang terhadap observasi yang telah dilaksanakan kepada responden dalam hal ini tentang usaha yang dilakukan untuk meningkatkan kompetensi guru mata pelajaran AlQur'an Hadiśt dalam mengelola pembelajaran di MAS Syekh Ahmad Basyir Parsariran Batang Toru Kabupaten Tapanuli Selatan.

b. Observasi

Observasi atau pengamatan langsung adalah kegiatan keseharian manusia dengan menggunakan panca indra mata sebagai alat bantu utamanya selain panca indra lainnya seperti telinga,penciuman, mulut, dan kulit . yang di maksud dengan metode observasi adalah metode pengumpulan data yang di gunakan untuk menghimpun data penelitian melalu pengamatan dan penginderaan. ${ }^{13}$ Teknik ini di gunakan agar penulis dapat melihat secara langsung keadaan lokasi penelitian dan untuk melengkapi sebagian data-data pokok yang diperlukan.

c. Dokumentasi

Dokumentasi adalah peninggalan tertulis mengenai berbagai kegiatan atau kejadian yang dari segi waktu relatif belum lama. Peninggalan tertulis dan jenis lainnya yang relatif sudah cukup lama berubah menjadi bukti-bukti historis (sejarah) mengenai keadaan, kejadian atau peristiwa masa lalu.

\section{HASIL PENELITIAN}

\section{A. Sejarah Singkat MAS Syekh Ahmad Basyir}

Parsariran desa Hapesong Baru Kecamatan Batangtoru adalah dahulunya merupakan suatu desa tempat rekreasi yang banyak di kunjungi berbagai penjuru, bahkan pendatang atau pengunjung yang datang ke desa tersebut banyak yang salah langkah atau menggunakan desa tersebut sebagai wahana maksiat. Oleh karenanya banyak muncul berbagai dinamika perilaku kaum muda mudi khususnya yang melakukan maksiat yang melanggar aturan- aturan dan nilai agama yang menghasilkan suatu perjinahan. Pada tahun 1983 muncul suatu pemikiran dari seorang tokoh islam

\footnotetext{
${ }^{11}$ Moh. Nasir, Metode Penelitian (Jakarta: Ghalia Indonesia, 1998), hal. 63

12 Slameto, Evaluasi Pendidikan (Jakarta: Rineka Cipta, 1998), hal. 131

${ }^{13}$ Burhan Bunging, penelitian kualitatif ( Jakarta : Kencana, 2011), hal, 118
} 
untuk membangun suatu lembaga pendidikan islam di desa tersebut untuk membendung ahlak masyarakat sekitar agar tidak terjerumus ke dalam lembah kemaksiatan. Syekh Ahmad Basyir adalah merupakan tokoh yang mendirikan Pondok pesantren tersebut untuk membina Ahlak khususnya bagi masyarakat sekitar. Tak lama kemudian setelah pesantren tersebut berdiri dan mengalami kemajuan pesantren tersebut mulai membangun sarana dan prasana madrasah.

Pada tahun 1989 Syekh Ahmad Basyir mendirikan Madrasah Aliyah . Pendirinya adalah Syek Ahmad Basyir, setelah beliau meninggal dilanjutkan oleh anaknya yang bernama KH. Mangaraja Kombang Nasution. Pimpinan Pesantren tersebut anaknya beliau KH. Mangaraja Kombang yang bernama Drs. H Mustanir Nasution. Jumlah Guru seluruh di MAS Syekh Ahmad Basyir sebanyak 8 orang.

Gambaran kompetensi guru dalam mengelola pembelajaran Al Qur'an Hadist di kelas, akan diuraikan secara sistematis yaitu:

1. Gambaran pembuatan satuan pembelajaran

Berdasarkan hasil wawancara dengan guru Al-Qur'an Hadist, bahwa pembuatan satuan pemebelajaran pelajaran Al-Qur'an Hadist pada saat pembelajaran adalah masih kurang. Dari data di atas dapat diketahui bahwa pembuatan satuan pembelajaran yang ada di MAS Syekh Ahmad Basyir Parsariran Batang Toru, Bapak/Ibu membuat satuan pembelajaran (100 \%) yang berkategori jarang. Dengan demikian dapat diambil suatu pengertian bahwa Bapak/Ibu jarang membuat satuan pembelajaran. Tabel di atas bila dihubungkan dengan hasil wawancara dengan guru Al-Qur'an Hadiśt sebelum pembelajaran selalu mempersiapkan dan membuat satuan pembelajaran. ${ }^{14}$

2. Gambaran perumusan tujuan pembelajaran dapat di dilihat pada tabel sebagai berikut:

TABEL 2

MERUMUSKAN TUJUAN PEMBELAJARAN

\begin{tabular}{|c|c|c|c|}
\hline No & $\begin{array}{l}\text { Alternatif } \\
\text { Jawaban }\end{array}$ & $F$ & Persentase \\
\hline 1. & Selalu & - & $0 \%$ \\
\hline 2. & Jarang & - & $0 \%$ \\
\hline 3. & Kadang- & 1 & $100 \%$ \\
\hline 4. & $\begin{array}{l}\text { kadang } \\
\text { Tidak pernah }\end{array}$ & - & $0 \%$ \\
\hline & Jumlah & 1 & $100 \%$ \\
\hline
\end{tabular}

Dari data di atas dapat diketahui bahwa guru mata pelajaran Al-Qur'an Hadiśt di MAS Syekh Ahmad Basyir Parsariran Batang Toru, guru jarang merumuskan tujuan pembelajaran.

Berdasarkan uraian tabel 2 di atas dihubungkan dengan hasil wawancara dengan guru mata pelajaran Al-Qur'an Hadiśt menyatakan bahwa proses pembelajaran tidak bisa

\footnotetext{
${ }^{14}$ Mawar Siregar /Guru al-Qur'an Hadiśt, Wawancara 5 Oktober 2014
} 
dilaksanakan dengan baik tanpa adanya perumusan tujuan pembelajaran. Tanpa adanya rumusan tujuan maka seorang guru tidak akan berhasil dalam menyampaikan dan pencapaian tujuan pembelajaran. ${ }^{15}$

Gambaran persiapan bahan pelajaran dapat dilihat pada tabel 4 berikut ini Selanjutnya mempersiapkan bahan pelajaran di MAS Syekh Ahmad Basyir Parsariran Batang Toru, yang berkenaan dengan mempersiapkan bahan pelajaran dapat dilihat seperti tabel 4 berikut ini:

TABEL 3

MEMPERSIAPKAN BAHAN PELAJARAN

\begin{tabular}{|c|l|c|c|}
\hline No & $\begin{array}{c}\text { Alternatif } \\
\text { Jawaban }\end{array}$ & F & Persentase \\
\hline 1. & Selalu & 1 & $100 \%$ \\
2. & Jarang & - & $0 \%$ \\
3. & Kadang- & - & $0 \%$ \\
4. & kadang & - & $0 \%$ \\
& Tidak & & \\
& pernah & & \\
\hline & Jumlah & 1 & $100 \%$ \\
\hline
\end{tabular}

Dari data di atas dapat diketahui guru mempersiapkan bahan pembelajaran di MAS Syekh Ahmad Basyir Parsariran Batang Toru, bahwa Bapak/Ibu selalu mempersiapkan bahan pembelajaran, (100\%) yang berkategori selalu. Dengan demikian dapat diambil suatu pengertian bahwa Bapak/Ibu selalu mempersiapkan bahan pembelajaran.

Berdasarkan uraian pada tabel 3 di atas dan dihubungkan dengan hasil wawancara dengan guru Al-Qur'an Hadiśt menyatakan bahwa apabila tidak ada persiapan bahan sebelum memulai proses belajar mengajar maka apabila pemberlajaran tidak akan bisa terarah dan tidak bisa mengkondisikan waktu dengan baik. ${ }^{16}$

Gambaran penyampaian TPK kepada siswa-siswi, terlihat pada tabel 5 berikut ini:

TABEL 4

MENYAMPAIKAN TPK KEPADA SISWA-SISWI

\begin{tabular}{|c|l|c|c|}
\hline No & \multicolumn{1}{|c|}{$\begin{array}{c}\text { Alternatif } \\
\text { Jawaban }\end{array}$} & F & Persentase \\
\hline 1. & Selalu & - & $0 \%$ \\
2. & Jarang & 1 & $100 \%$ \\
3. & Kadang- & - & $0 \%$ \\
4. & kadang & - & $0 \%$ \\
& Tidak pernah & & \\
\hline & Jumlah & 1 & $100 \%$ \\
\hline
\end{tabular}

Dari data di atas dapat dilihat bahwa guru mata pelajaran Al-Qur'an Hadiś dalam menyampaikan TPK di MAS Syekh Ahmad Basyir Parsariran Batang Toru (100 \%) yang berkategori jarang,

Dengan demikian dapat diambil suatu pengertian bahwa Bapak/Ibu Al-Qur'an Hadiśt tidak menyampaikan TPK kepada siswa-siswi.

\footnotetext{
${ }^{15}$ Mawar Siregar /Guru al-Qur'an Hadiś Wawancara 5 Oktober. 2014

${ }^{16}$ Mawar Siregar/Guru al-Qur'an Hadiś Wawancara Cara Tanggal 5 Okober 2014
} 
Hal ini jika dihubungan dengan hasil wawancara dengan guru Al-Qur'an Hadiśt dapat di kategorikan tidak pernah menyampaikan TPK kepada siswa-siswi.

Dan berdasarkan observasi dengan ibu Mawar Siregar dalam proses pembelajaran bahwa tidak menyampaikan TPK karena keterlambatan menyajikan materi pelajaran, apabila sebelum menyampaikan TPK takut kekurangan waktu untuk menyampaikan materi pelajaran.

Gambaran pengadaan appersepsi pada kegiatan awal pembelajaran. Selanjutnya mengadakan appersepsi pada kegiatan awal pembelajaran di MAS Syekh Ahmad Basyir Parsariran Batang Toru oleh guru mata pelajaran Al-Qur'an Hadiśt , terlihat pada tabel 6 sebagai berikut:

\section{TABEL 5}

MENGADAKAN APPERSEPSI PADA KEGIATAN

AWAL PEMBELAJARAN

\begin{tabular}{|c|l|c|c|}
\hline No & \multicolumn{1}{|c|}{$\begin{array}{c}\text { Alternatif } \\
\text { Jawaban }\end{array}$} & F & Persentase \\
\hline 1. & Selalu & - & $0 \%$ \\
2. & Jarang & 1 & $100 \%$ \\
3. & Kadang-kadang & - & $0 \%$ \\
4. & Tidak pernah & - & $0 \%$ \\
\hline & Jumlah & 1 & $100 \%$ \\
\hline
\end{tabular}

Dari data di atas dapat dapat diketahui bahwa mengadakan appersepsi pada kegiatan awal kegiatan awal pelajaran di di MAS Syekh Ahmad Basyir Parsariran Batang Toru, terlihat tidak terlaksana dengan baik, karena hanya (100\%) yang berkategori jarang . Dengan demikian dapat diambil suatu pengertian bahwa Bapak/Ibu Al-Qur'an Hadist Kurang dalam mengadakan appersepsi.

Berdasarkan uraian pada tabel 5 di atas dan bila di hubungkan dengan hasil wawancara dengan guru mata pelajaran Al-Qur'an Hadiśt menyatakan bahwa mengadakan appersepsi pada kegiatan awal pembelajaran masih kurang. Dan berdasarkan observasi adanya kekurangan guru mata pelajaran Al-Qur'an Hadiśt dalam mengadakan appersepsi, sehingga siswa-siswi kurang dalam menguasai bahan pelajaran yang telah disampaikan guru, dan apabila dihubungkan dengan tabel 7 di bawah ini bahwa guru Al-Qur'an Hadiśt dalam pemberian motivasi masih sangat lemah sehingga banyak siswa-siswi yang kurang berminat dalam mengikuti mata pelajaran Al-Qur'an Hadiśt, adapun motivasi yang diberikan guru al-Qur'an Hadiśt kepada siswa-siswi terlihat pada tabel 7 Berikut ini:

TABEL 6

PELAKSANAAN MOTIVASI BELAJAR SISWA-SISWI DISEKOLAH

\begin{tabular}{|c|l|c|c|}
\hline No & \multicolumn{1}{|c|}{$\begin{array}{c}\text { Alternatif } \\
\text { Jawaban }\end{array}$} & F & Persentase \\
\hline 1. & Selalu & - & $0 \%$ \\
2. & Jarang & 1 & $100 \%$ \\
3. & Kadang-kadang & - & $0 \%$ \\
4. & Tidak pernah & - & $0 \%$ \\
\hline \multicolumn{2}{|c|}{ Jumlah } & 1 & $100 \%$ \\
\hline
\end{tabular}


Dari data di atas dapat diketahui bahwa pelaksanaan motivasi belajar siswa-siswi di MAS Syekh Ahmad Basyir Parsariran Batang Toru, terlihat lemah, hanya berkategori jarang (100 \%). Dengan demikian dapat diambil suatu kesimpulan bahwa dalam pelaksanaan motivasi belajar siswa-siswi guru mata pelajaran Al-Qur'an Hadiśt masih lemah.

Gambaran Pengadaan Pretest Pada kegiatan awal proses belajar mengajar dapat dilihat pada tabel 8 sebagai berikut:

TABEL 7

MENGADAKAN PRETEST PADA KEGIATAN AWAL PROSES BELAJAR-MENGAJAR

\begin{tabular}{|c|l|c|c|}
\hline No & \multicolumn{1}{|c|}{$\begin{array}{c}\text { Alternatif } \\
\text { Jawaban }\end{array}$} & F & Persentase \\
\hline 1. & Selalu & - & $0 \%$ \\
2. & Jarang & 1 & $100 \%$ \\
3. & Kadang-kadang & - & $0 \%$ \\
4. & Tidak pernah & - & $0 \%$ \\
\hline & \multicolumn{1}{|c|}{ Jumlah } & 1 & $100 \%$ \\
\hline
\end{tabular}

Dari data di atas dapat dapat diketahui mengadakan pretest pada kegiatan awal proses belajar mengajar di MAS Syekh Ahmad Basyir Parsariran Batang Toru, Bapak/Ibu selalu mengalami kendala dalam hal mengadakan pretest karena kurangnya kedisiplinan guru yaitu seringnya terlambat dalam penyajian pelajaran, hanya (100\%) yang berkategori jarang. Dengan demikian dapat diambil suatu kesimpulan bahwa guru mata pelajaran AlQur'an Hadiśt masih dikategorikan kurang dalam hal mengadakan pretest pada kegiatan awal proses belajar mengajar.

Dari data di atas jika dihubungkan dengan hasil wawancara dengan guru mata pelajaran Al-Qur'an Hadiśt menyatakan bahwa mengadakan pretest pada kegiatan awal proses belajar-mengajar masih jarang dilaksanakan hal ini karena seringnya keterlambatan masuk kelas untuk menyajikan bahan pelajaran, hal ini terjadi karena tidak tersedianya kantor guru.

Pretest adalah pertanyaan-pertanyaan yang diberikan guru pada saat awal pelajaran, sebelum masuk pelajaran yang akan datang. Pretest sangat baik dikerjakan untuk mengetahui kemampuan siswa-siswi dalam menguasai pelajaran yang telah lalu dan dikaitkan dengan pelajaran yang akan di sajikan dan untuk mengulang kembali pelajaran yang telah lalu.

Gambaran Penggunaan metode dalam proses pembelajaran, dapat dilihat pada tabel 9, sebagai berikut:

Selanjutnya menggunakan metode dalam proses pembelajaran di MAS Syekh Ahmad Basyir Parsariran Batang Toru dapat di lihat pada tabel 9 berikut ini:

TABEL 8

MENGGUNAKAN METODE DALAM

PROSES BELAJAR MENGAJAR

\begin{tabular}{|c|c|c|c|}
\hline No & $\begin{array}{c}\text { Alternatif } \\
\text { Jawaban }\end{array}$ & F & Persentase \\
\hline 1. & Selalu & 1 & $100 \%$ \\
\hline
\end{tabular}




\begin{tabular}{|c|l|c|c|}
\hline 2. & Jarang & - & $0 \%$ \\
3. & Kadang-kadang & - & $0 \%$ \\
4. & Tidak pernah & - & $0 \%$ \\
\hline & Jumlah & 1 & $100 \%$ \\
\hline
\end{tabular}

Dari data di atas dapat dapat diketahui menggunakan metode dalam proses belajar mengajar di MAS Syekh Ahmad Basyir Parsariran Batang Toru, Bapak/Ibu selalu menggunakan metode dalamproses belajar-mengajar $(100 \%)$ yang berkategori selalu. Dengan demikian dapat diketahui bahwa menggunakan metode dalam proses belajarmengajar guru mata pelajaran Al-Qur'an Hadiśt selalu menggunakan metode.

Berdasarkan uraian pada tabel 8 di atas dan bila dihubungkan dengan hasil wawancara dengan guru mata pelajaran Al-Qur'an Hadiśt Menyatakan bahwa guru mata pelajaran Al-Qur'an Hadiśt dalam menyampaikan bahan pelajaran selalu menggunakan matode, "Bagaimana menyampaikan bahan pelajaran tanpa menggunakan metode, paling tidak metode ceramah". Metode merupakan cara guru menyampaikan pelajaran kepada siswa-siswi, tanpa metode yang sesuai proses belajar-mengajar tidak bisa di capai dengan afektif, efisien dan menyenangkan.

Gambaran guru penggunaan media dalam proses pembelajaran dapat dilihat pada tabel 10 berikut ini:

\section{TABEL 9}

MENGGUNAKAN MEDIA DALAM PROSES PEMBELAJARAN

\begin{tabular}{|c|l|c|c|}
\hline No & \multicolumn{1}{|c|}{$\begin{array}{c}\text { Alternatif } \\
\text { Jawaban }\end{array}$} & F & Persentase \\
\hline 1. & Selalu & - & $0 \%$ \\
2. & Jarang & - & $0 \%$ \\
3. & Kadang-kadang & 1 & $100 \%$ \\
4. & Tidak pernah & - & $0 \%$ \\
\hline & \multicolumn{1}{|c|}{ Jumlah } & 1 & $100 \%$ \\
\hline
\end{tabular}

Dari data di atas dapat dapat diketahui penggunaan media dalam proses belajar mengajar berkategori kurang di MAS Syekh Ahmad Basyir Parsariran Batang Toru, hanya (100\%) yang berkategori kadang-kadang. Dengan demikian dapat diketahui bahwa guru mata pelajaran Al-Qur'an Hadiśt dalam menggunakan media dalam proses pembelajaran dikategorikan lemah dan kurang.

Dari uraian di atas bila dihubungkan dengan hasil wawancara dengan guru mata pelajran Al-Qur'an Hadiśt menyatakan bahwa menggunakan media dalam proses pembelajaran menggalami kendala, seperti kurangnya alat-alat peraga, dan operasional saat terjadi proses belajar mengajar, bahkan berdasarkan observasi penulis terlihat ketika berlangsunya proses belajar-mengajar minimnya sarana-prasarana dalam belajar seperti halnya dalam penggunaan media disekolah tersebut.

Gambaran pengaturan siswa, waktu dan fasilitas belajar, dapat dilihat pada tabel 11 berikut ini:

Selanjutnya kompetensi guru mata pelajaran Al-Qur'an Hadiśt dalam mengelola pembelajaran melalui pengaturan siswa, waktu dan fasilitas belajar dapat dilihat pada tabel 10 sebagai berikut: 
TABEL 10

MENGATUR SISWA, WAKTU DAN FASILITAS BELAJAR

\begin{tabular}{|c|l|c|c|}
\hline No & \multicolumn{1}{|c|}{$\begin{array}{c}\text { Alternatif } \\
\text { Jawaban }\end{array}$} & F & Persentase \\
\hline 1. & Selalu & 1 & $100 \%$ \\
2. & Jarang & - & $0 \%$ \\
3. & Kadang-kadang & - & $0 \%$ \\
4. & Tidak pernah & - & $0 \%$ \\
\hline & Jumlah & 1 & $100 \%$ \\
\hline
\end{tabular}

Dari data di atas dapat dapat diketahui kompetensi guru mata pelajaran Al-Qur'an Hadiśt dalam mengelola pembelajaran melalui pengaturan siswa, waktu dan fasilitas belajar di MAS Syekh Ahmad Basyir Parsariran Batang Toru $100 \%$ yang berkategori selalu. Dengan demikian dapat diambil suatu pengertian bahwa kompetensi guru mata pelajaran Al-Qur'an Hadiśt dalam mengelola pembelajaran melalui pengetahuan siswa, waktu dan fasilitas belajar selalu mengatur siswa, waktu dan fasilitas belajar.

Dari uraian di atas bila dihubungkan dengan hasil wawancara bahwa kompetensi guru mata pelajaran Al-Qur'an Hadiśt dalam mengelola pembelajaran melalui mengatur siswa, waktu dan fasilitas belajar bahwa proses belajar tidak bisa berlangsung dengan baik tanpa adanya pengaturan yang baik dari seorang guru yang berkompetensi. Berdasarkan observasi penulis melihat bahwa guru mata pelajaran Al-Qur'an Hadiśt dalam mengelola kelas masih terdapat kendala dan kelemahan, karena adanya guru yang sibut sendiri dan kurang memperhatikan keadaan siswa-siswi.

Gambaran pelaksanaan post test, dapat terlihat pada tabel 11, berikut ini:

Selanjutnya kompetensi guru mata pelajaran Al-Qur'an Hadiś dalam mengelola pembelajaran melalui post test, dapat terlihat pada tabel 11 di bawah ini:

\section{TABEL 11}

MELAKSANAKAN POST TEST PADA KEGIATAN AKHIR

\begin{tabular}{|c|l|c|c|}
\hline No & \multicolumn{1}{|c|}{$\begin{array}{c}\text { Alternatif } \\
\text { Jawaban }\end{array}$} & F & Persentase \\
\hline 1. & Selalu & - & $0 \%$ \\
2. & Jarang & - & $0 \%$ \\
3. & Kadang-kadang & 1 & $100 \%$ \\
4. & Tidak pernah & - & $0 \%$ \\
\hline & Jumlah & 1 & $100 \%$ \\
\hline
\end{tabular}

Dari data di atas dapat dapat diketahui kompetensi guru mata pelajaran Al-Qur'an Hadiś dalam mengelola pembelajaran melalui pelaksanaan post test pada kegiatan akhir proses pembelajaeran, $(100 \%)$ yang berkategori kadang-kadang. Dengan demikian dapat diketahui bahwa kompetensi guru mata pelajaran Al-Qur'an Hadiśt dalam mengelola pembelajaran pelaksanaan post test pada kegiatan akhir proses pembelajaran masih kurang.

Uraian di atas, bila dihubungan dengan hasil wawancara dengan guru mata pelajaran Al-Qur'an Hadiśt menyatakan bahwa post test tidak terlalu sering dilaksanakan karena adanya kendala kekurangan waktu. 
Gambaran penyimpulan pelajaran, dapat dilihat pada tabel 12, sebagai berikut:

TABEL 12

MENYIMPULKAN PELAJARAN PADA

KEGIATAN AKHIR PROSES PEMBELAJARAN

\begin{tabular}{|c|l|c|c|}
\hline No & \multicolumn{1}{|c|}{$\begin{array}{c}\text { Alternatif } \\
\text { Jawaban }\end{array}$} & F & Persentase \\
\hline 1. & Selalu & 1 & $100 \%$ \\
2. & Jarang & - & $0 \%$ \\
3. & Kadang-kadang & - & $0 \%$ \\
4. & Tidak pernah & - & $0 \%$ \\
\hline & Jumlah & 1 & $100 \%$ \\
\hline
\end{tabular}

Dari data di atas dapat dapat suatu kesimpulan bahwa kompetensi guru mata pelajaran Al-Qur'an Hadiśt dalam mengelola pembelajaran melalui menyimpulkan pelajaran $(100 \%)$ yang berkategori selalu. Dengan demikian dapat diambil suatu kesimpulan bahwa selalu menyimpulkan pembelajaran pada kegiatan akhir proses pembelajaran.

Data di atas bila dihubungkan dengan hasil wawancara guru mata pelajaran AlQur'an Hadiśt menyatakan bahwa sebelum menutup pelajaran terlebih dahulu menyimpulkan pelajaran. Menyimpulkan suatu pelajaran adalah hal yang sangat penting dengan penyimpulan pelajaran siswa-siswi bisa lebih memahami isi pembelajaran.

Gambaran pemberian tidak lanjut pada kegiatan akhir pembelajaran, dapat di lihat pada tabel 14 berikut ini:

Selanjutnya kompetensi guru mata pelajaran Al-Qur'an Hadiśt dalam mengelola pembelajaran melalui memberi tindak lanjut pada kegiatan akhir pembelajaran, terlihat pada tabel 13 sebagai berikut:

TABEL 13

MEMBERI TINDAK LANJUT PADA

KEGIATAN AKHIR PROSES PEMBELAJARAN

\begin{tabular}{|c|l|c|c|}
\hline No & \multicolumn{1}{|c|}{$\begin{array}{c}\text { Alternatif } \\
\text { Jawaban }\end{array}$} & F & Persentase \\
\hline 1. & Selalu & - & $0 \%$ \\
2. & Jarang & 1 & $100 \%$ \\
3. & Kadang-kadang & - & $0 \%$ \\
4. & Tidak pernah & - & $0 \%$ \\
\hline & \multicolumn{1}{|c|}{ Jumlah } & 1 & $100 \%$ \\
\hline
\end{tabular}

Data di atas dapat dapat suatu pengertian bahwa kompetensi guru mata pelajaran Al-Qur'an Hadiśt dalam mengelola pembelajaran melalui pemberian tindak lanjut pada kegiatan akhir proses pembelajaran, hanya (100\%) yang berkategori jarang. Dengan demikian dapat di ketahui bahwa kompetensi guru mata pelajaran Al-Qur'an Hadiśt kurang dalam hal memberikan tinmdak lanjut untuk mengelola pembelajaran. 
Uraian di atas, jika dihubungkan dengan hasil wawancara dengan guru Al-Qur'an Hadiśt menyatakan bahwa memberikan tindak lanjut pada kegiatan akhir pembelajaran masih sangat jarang dilakukan, karena kekurangan pasilitas yang disediakan oleh pihak sekolah.

Gambaran pemberian nasehat, dapat dilihat pada tabel 14 sebagai berikut:

\section{TABEL 14} MEMBERI NASEHAT

\begin{tabular}{|c|l|c|c|}
\hline No & \multicolumn{1}{|c|}{$\begin{array}{c}\text { Alternatif } \\
\text { Jawaban }\end{array}$} & F & Persentase \\
\hline 1. & Selalu & 1 & $100 \%$ \\
2. & Jarang & - & $0 \%$ \\
3. & Kadang-kadang & - & $0 \%$ \\
4. & Tidak pernah & - & $0 \%$ \\
\hline & Jumlah & 1 & $100 \%$ \\
\hline
\end{tabular}

Data di atas dapat dapat di ketahui bahwa kompetensi guru mata pelajaran al-Qur'an Hadiś dalam mengelola pembelajaran melalui pemberian nasehat (100\%) yang berkategori selalu. Dengan demikian dapat diambil suatu kesimpulan bahwa kompetensi guru mata pelajaran al-Qur'an Hadiś kurang dalam hal pemberian nasehat.

Uraian di atas bila dihubungkan hasil wawancara dengan guru mata pelajaran alQur'an Hadiś menyatakan pemberian nasehat sangat dibutuhkan oleh siswa-siswi. Dan sebagaian yang lain mengatakan bahwa dalam pemberian nasehat jika siswa tersebut mempunyai masalah.

\section{PENUTUP}

\section{A. Kesimpulan}

Dari beberapa uraian diatas dapat penulis simpulkan sebagai berikut:

1. Kompetensi guru dalam mengelola pembelajaran Al-Qur'an Hadiśt di MAS Syekh Ahmad Basyir Parsariran Batang Toru, berada pada kategori rendah, karena masih kurang dalam megadakan pretest, mengabaikan tujuan pembelajaran khusus (TPK), kurangnya dalam menggunakan apersepsi, kurangnya dalam mengadakan free test, kurangnya menggunakan metode pembelajaran, kurangnya dalam menggunakan media, dan kurangnya dalam meberikan tindak lanjut pembelajaran.

2. Bahwa upaya pembenukan kompetensi guru mata pelajaran Al-Qur'an Hadiśt di MAS Syekh Ahmad Basyir Parsariran Batang Toru adalah : menumbuhkan kreatifitas guru, mengikuti penataran loka karya, Latar belakang pendidikan guru dengan menyarankan guru melanjutkan pendidikan ke jenjang yang lebih tinggi, mengikuti seminar atau pelatihan, mengikuti program-program yang di upayakan pihak sekolah, membaca buku yang relevan, mengikuti workshop dan diklat yang di selenggarakan pihak pemerintah maupun swasta, dan akan melanjutkan pendidikan ke jenjang yang lebih tinggi. Selain dari pada itu guru Al-Qur'an Hadist juga selalu berusaha melakukan sharing atau dialog dengan orang yang lebih berpengalaman untuk menambah wawasan dan pengetahuan yang dimilikinya.

\section{B. Saran-saran}


1. Kepada semua guru mata pelajaran Al-Qur'an Hadiśt agar betul-betul berupaya untuk meningkatkan kompetensinya dalam pengelolaan pembelajaran untuk menunjang tercapainya tujuan pembelajaran yang baik.

2. Diharapkan kepada pihak sekolah agar selalu berupaya untuk meningkatkan kompetensi guru, dan bekerja sama dengan guru-guru bidang studi untuk mengetahui kekurangan-kekurangan yang dibutuhkan.

\section{Daftar Pustaka}

Arikunto, Suharsimi, Prosedur Penelitian Suatu Pendekatan Praktek, Jakarta: Rineka Cipta, 1996.

B Uno, H. Hamzah, Profesi Kependidikan, Jakarta: PT Bumi Aksara, 2008.

Bungin, Burhan, Penelitian Kualitatif, Jakarta : Kencana, 2011

Djamarah, Bahri, Syaiful, Guru dan Anak Didik, Jakarta: Rineka Cipta, 2000.

Gunawan, H., Kebijakan-kebijakan Pendidikan di Indonesia, Jakarta: Bina Aksara, 1906.

Hamalik, Oemar, Pendidikan Guru Berdasarkan Kompetensi, Bandung: PT Rosda Karya, 2002.

Margono, S, Metodologi Penelitian Pendidikan Jakarta: Rineka Cipta, 2010

Marwan, Bunga Rampai (Pendidikan Agana Islam), Jakarta: Diroktorat Jendral Kelembagaan Agama Islam, 1999 .

Miles, B, M. and Huberman Michel, A, Qualitatif Data Analisis, Bevery Hills USA: Sage Pulication, 1984

Moleong, Lexi J, Metodologi Penelitian Qualitatif, Bandung: PT Remaja Rosdakarya , 1994

Mulyasa, E., Standar dan Kompetensi dan Serbifikasi guru, Bandung: PT Rosdakarya, 2007

Musfah, Jejen, Peningkatan Kompetensi Guru Jakarta: Kencana Prenada Media Group, 2012

Namsa, Yunus, Metode Pengajaran Agama Islam, Jakarta: Firdaus, 2000.

Nasir, Moh., Metode Penelitian, Jakarta: Ghalia Indonesia, 1998.

Nasution, S., Didaktik Asas-asas Mengajar, Bandung: Jemmars, 1982

Nasution, Mustanir /Kepala Sekolah, Wawancara Tanggal 6 Oktober 2014.

Nawawi, Hadari, Instrumen Penelitian Bidang Sosial, Yogyakarta: Gajah Mada University Press, 2006

Rahman, Abdul, Saleh, , Pendidikan Agama dan Keagamaan, Jakarta: PT. Gemawindu Pancaperkasa, 2000 .

Sabri, Alisuf, Mimbar Agama dan Budaya,Cet. Ke-I, Jakarta: Pusat Penelitian dan Pengabdian pada Masyarakat IAIN, 1992. 
